\title{
Sneaking through the minefield of talent management: the notion of rhetorical obfuscation
}

\author{
Huang, J. and Tansley, C. (2012) International Journal of HRM.
}

\begin{abstract}
In spite of the growing popularity of talent management in practice there has been a distinct lack of theoretical attention paid by scholars to such a strategically important innovation. To address this shortfall, we conducted an in-depth case study of a multinational enterprise (MNE) to examine and conceptualise the rhetorical underpinnings of its efforts in implementing a talent management programme. Based on our findings, we propose the notion of rhetorical obfuscation to conceptualise the intentional use of persuasive language to selectively project and communicate organisational agenda as a means of directing and reinforcing relevant stakeholders' commitments and conforming behaviours. In particular, we found that rhetorical obfuscation was used extensively in the case organisation to cover up inconsistency in practices and lack of legitimacy during the institutionalisation of talent management. Our contributions are threefold. Firstly, this study has provided a necessary theoretical grounding to conceptualise talent management. Secondly, by introducing the theory of rhetorical practice to HR innovation research, our account has demonstrated the usefulness of rhetorical practice and created a launch pad for other HR researchers to build upon. Thirdly, by exploring the rhetorical underpinnings related to the adoption of talent management, we have added to the rich intellectual tradition of rhetorical practice by presenting the notion of rhetorical obfuscation.
\end{abstract}

Key words: talent management, rhetorical practice, rhetorical obfuscation, innovation diffusion 


\section{Sneaking through the minefield of talent management: the notion of rhetorical obfuscation}

\section{INTRODUCTION}

Despite a growing popularity in practice, research related to process innovation, in particular those which put human resourcing (HR) in a central position, is extremely limited (Zanko, Badham, Couchman and Schubert 2008). Contributing to the overriding debates and limited conceptualisation of HR innovation, the focus of this study is on an evolving HR practice called talent management. Talent management is an HR practice aimed at addressing competition for high value labour in widening global markets alongside key employees' demand for fast-track career development (Collings and Mellahi 2009; Mellahi and Collings 2010). Although consensus in the main elements and scope of this practice are yet to be reached (CIPD 2007), talent management is argued to consist of a set of processes for succession planning and accelerated development paths, typically for executive level roles, aimed at those employees with the highest potential who also demonstrate a capacity for high performance (Cappelli 2008). More recently, Mellahi and Collings (2010) have provided an indicative landscape which maps out the key streams of talent management research and practice, including: the identification of key positions for the creation of competitive advantage, the construction of talent pools, and rewarding of talented people. The importance of talent management is reflected not only in its strategic contribution to an organisation's overall competitiveness (Collings and Mellahi 2009), but also in an organisation's ability to architect, manage and sustain its knowledge base (Scullion, Collings and Caligiuri 2010).

As an HR innovation, talent management has some rather unique characteristics, not least a tendency to focus exclusively on elite high performers in terms of managing their development, promotion and retention in order to align with the strategic needs of the organisation. This tendency towards such an exclusive mode of talent management can bring a number of challenges. Firstly, such a mode of exclusivity is argued to be a source of hazardous conditions that can threaten an organisation's health (Pfeffer 2001). For example, an organisation can fail to establish and sustain the 
necessary legitimacy when institutionalising an innovation that has a very weak consensus base amongst its stakeholders (Sillince, Harindranath and Harvey 2001) and this can cause serious employment relations problems which can threaten the survival of the organisation. Secondly, an exclusive approach can be deemed to be politically incorrect, thus fundamentally acting against the principle of equal opportunity that many organisations strike to achieve. To avoid any debate about its political correctness, some organisations, as shown in the CIPD report (2007), have taken a secretive approach when introducing talent management programmes. There are several notable reasons for this, which we will examine later in the paper.

Resulting from these factors and the way they are combined, talent management is therefore a highly contentious innovation that requires further critical examination. With very few exceptions, such as Mellahi and Collings (2010) who theorise the failures of talent management, the lack of adequate conceptualisation to accurately pinpoint the theoretical meanings and practical consequences of talent management has inspired us to take one step back by examining how an innovation like talent management is discursively constructed by its stakeholders. For such an endeavour, few theoretical perspectives can address the discursive element of an innovation better than rhetoric (Green 2004)

\section{Rhetoric - the discursive element of an innovation}

Beginning as an art for persuasion in ancient Greek society, the conceptual grounding of rhetoric has gone through several critical renaissances (Herrick 1998). However, the most relevant aspect of rhetoric to this study is the way it is used in practice by different organisational actors to construct, express and make sense of their own realities and agendas, which are then tactically broadcasted to their intended audiences (Sillince 2005). In particular, when innovation adoption becomes the main driver of institutional change (Tolbert and Zucker 1983), mobilised rhetorics and rhetorical practice can become a vital source to yield valuable insights into the institutionalisation of such innovation (Sillince, Marindranth and Harvey 2001; Green 2004; Suddaby and Greenwood 2005). Despite the fact such rhetorical practice is an essential aspect of organisational life and an essential mechanism to institutionalise innovation (Sillince et al. 2001), its theoretical potential is 
relatively under-valued (Green 2004). For example, Suddaby and Greenwood argue that 'scholars have paid inadequate attention to the process by which the use of persuasive language directly affects access to resources, shapes markets, or influences performance' $(2005, \mathrm{p}$. 62). This situation is also specifically reflected in HR research (Grant 1999). To address this shortfall, the aim of this paper is to examine and conceptualise the rhetorical underpinnings of a talent management programme adopted by a multinational corporation. Based on an in-depth case study, we have explored, documented and analysed the rhetorical practice that was developed and enacted by the relevant stakeholders to institutionalise talent management, as well as to compensate and cover up the lack of legitimacy. Emerging from our analysis, we propose the notion of rhetorical obfuscation to conceptualise "the intentional use of persuasive language to selectively project and communicate organisational agenda as a means of directing and reinforcing relevant stakeholders' commitments and conforming behaviours'. The significance of rhetorical practice, in particular the notion of rhetorical obfuscation proposed and illustrated in our study, allows us to show how such an endeavour is unobtrusively woven into the fabric of our working life.

The paper is structured as follows. We first introduce the intellectual traditions that form the basis of rhetorical practice, particularly relating the conceptual elements of rhetoric to the context of innovation. Second, we outline the methodological details and rationale that underlie our research design, data collection methods and data analysis strategy. Third, to elaborate our case findings, we have developed a storyline to reflect the journey through which the case organisation and its related stakeholders have been through during the adoption of talent management. Fourth, the notion of rhetorical obfuscation is presented to showcase our core findings. We conclude by identifying both theoretical implications of rhetorical practice and rhetorical obfuscation.

\section{RHETORIC IN THE CONTEXT OF INNOVATION}

Rhetoric represents 'the humanistic tradition for the study of persuasion' (Cheney, Christensen, Conrad and Lair 2004, p. 79), and manifests actors' arguments-in-use (Suddaby and Greenwood 2005). With the unique characteristic and objective of achieving persuasion, a rhetorical practice 
typically consists of several interconnected elements, including the emergence of rhetorical situations, the devising and deployment of rhetorical strategies and the interplay amongst engaged actors. For rhetoric to function effectively, a rhetor (Eccles, Nohria and Berkley 1992) needs to assess the rhetorical situation and explore the entrepreneurial opportunity that the rhetorical situation can afford. Often, intended rhetorical outcomes can be jeopardised, if the rhetor fails to obtain sufficient understanding about the targeted audiences' tastes and preferences. There are two fundamental explanations for this. First, constructing rhetorical content is as crucial as choosing how to deliver the rhetoric itself (Hirsch 1986; Alvesson and Kärreman 2000). Second, given that rhetorical practice is politically geared and interest-laden, the underlying value proposition of a rhetorical statement needs to be congruent with the orientation of the target audience (Sillince 2005), or at least provide room and scope for the congruence to be nurtured (Freedman and Medway 1994). As suggested by Cheney, et al. (2004, p. 82) 'a rhetorical syllogism employs probability statements whose "truth" depends on conformity to the audience's beliefs and the functions of the syllogism in everyday talk'. Furthermore, rhetorical contestation often occurs not only between different rhetors (Sillince et al. 2001), but also in the use of different rhetorics by the same rhetor. Hence, rhetoric represents more than just the understanding and evaluation of the rhetorical situations and their related uncertainties and implications, but also characterises a rhetor's ability to select and shape the rhetorical strategies to communicate with, in many cases manipulate, the target audiences in order to compete for the dominating position (Cheney et al. 2004; Suddaby and Greenwood 2005).

As reflected by Suddaby and Greenwood (2005, p. 41), 'actors employ rhetorical devices to connect elements of the existing or proposed form to broader cultural understandings in an effort to support or challenge comprehensibility of an innovation'. The need for gaining a dominant position is particularly apparent in various forms of organisational innovation, such as institutional change (Suddaby and Greenwood 2005; Erkama and Vaara 2009). In the context of innovation, in particular the process to institutionalize it (Tolbert and Zucker 1996), rhetoric plays several key parts (Sillince et al. 2001; Green 2004). First, according to Green (2004), rhetoric is the vehicle by which innovation in the adoption and institutionalisation process can be purposefully promoted, debated and institutionalised. As suggested by Sillince (2005, p. 611), 'switching perspective entails taking the 
view that power is held by (several) interest groups who set out to enrich their rhetoric by demonstrating an ability to internalize that plurality. Each of several interest groups' voices is treated differently, is quoted, co-opted, dismissed, or appropriated'. Specifically, through rhetorical exchange, or switching perspective in Sillince's terms, fits and misfits between the underlying ideology and its alternative interpretations of an innovation and an organisation's embedded institutional logic can be publicly contested (Sillince et al. 2001; Green, Li and Nohria 2009).

Second, closely related to the first point, rhetorical practices are deployed to gain wider stakeholder support in order to achieve or resist legitimacy of an innovation (Sillince et al. 2001; Suddaby and Greenwood 2005; Erkama and Vaara 2009; Green et al. 2009). Based on an in-depth case study of a global organization's journey to overcome resistance encountered during restructuring, Erkama and Vaara (2009) portray the discursive struggles underlying the process of establishing legitimacy. Two key contributions of their study are strongly relevant when investigating and theorising the use of rhetoric in innovation adoption. On the one hand, it is crucial to take into account the broader organisational, political and cultural discourses that are expressed by different actors at various stages of innovation adoption. On the other, there is a strong need to make sense of how different rhetorical elements and resources are accessible and mobilised by the rhetors to form their rhetorical strategies (Suddaby and Greenwood 2005). Therefore, rhetorical practice, in particular in the context of innovation adoption, is highly demanding on actors' abilities to improvise and capitalise on any potential margin that is available to them (Vaara and Tienari 2008).

Third, understanding the role of rhetoric helps to challenge some of the dominant innovation adoption frameworks, such as accounts by Rogers (1995) on technology and Mone, McKinley and Baker (1998) and Rajagopal (2002) on process innovation. As criticised by Green (2004), the underlying assumption commonly shared by these dominant innovation adoption frameworks is that the adoption decision is largely driven by the intrinsic benefits of innovation (No. 1). Based on these dominant innovation adoption frameworks, as far as an innovation can generate return on investment to an organisation or its parts, these benefits can be objectively presented to and clearly understood by its stakeholders. What these frameworks fail to address is firstly that different stakeholders tend not to share a universal view towards the value of an innovation and secondly that actors, in order to appeal 
more to targeted audiences, entrepreneurially construct rhetorical statements which highlight certain features and attributes while downplaying others (Suddaby and Greenwood 2005). By accentuating this we more clearly understand that knowing how values are discursively created and projected can be as fundamental as making sense of the values themselves (Cheney et al. 2004; Green et al. 2009).

It is vital to note that, in the context of innovation adoption and its institutionalization, rhetorical practice is not merely performed by internal stakeholders who champion or challenge the new ideology (Sillince et al. 2001; Green 2004). External stakeholders, such as management consultants, universities or professional associations, can be rather influential in utilising their rhetoric to enhance the popularity of an innovation (Abrahamson 1996; Newell, Swan and Galliers 2000; Sillince et al. 2001; Tansley and Newell 2007; Huang, Galliers, Hsu and Newell 2011). Abrahamson (1996) suggests that for trendsetters to gather a crowd, they need to be multi-skilled in articulating the emergent preferences of the fashion seekers, as well as in developing rhetoric that can help fashion seekers to visualise the benefits afforded by the innovation. In addition to the essential characteristics of being accessible and rich in values, the rhetoric needs to be relatively easy for the fashion seekers to mobilise for further consumption. This is because, for the fashion to spread and flourish, the fashion seekers themselves need to be able to take on the role of a rhetor to reach the potential audiences to secure their support for the innovation. Therefore, it is clear that the catchment area of a rhetor cannot be limited to just the actors who initiate and populate the rhetoric. Rather, it should also take into account those in the audience who can potentially become a rhetor themselves. Furthermore, given that 'rhetoric is an essential element of the deliberate manipulation of cognitive legitimacy' (Suddaby and Greenwood 2005, p. 40), self-interest hidden behind a rhetor's motivation cannot be ignored (Newell, Tansley and Huang 2004).

Different innovation occasions call for different rhetorical responses (Cheney et al. 2004; Green 2004) and different blends of rhetorical strategies (Sillince 2005). The multi-faceted and fluid nature of rhetorical practice is greatly amplified in the context of innovation adoption and its institutionalisation, as the legitimacy of previously dominant norms are under threat and creating room for alternatives to germinate (Tolbert and Zucker 1996). Undoubtedly, uncertainties associated with an innovation play a key part in affording the opportunities for different rhetors to showcase their 
attempts. Hence, the way different rhetorics compete for attention and dominance can provide a highly rich theoretical milieu where the underlying meanings, hidden agenda and unspoken assumptions of an innovation can be critically unpacked and discursively understood (Suddaby and Greenwood 2005; Green et al. 2009). Despite the need for rhetoric, Green (2004) argues that the intensity of rhetorical exchange will gradually die down once an innovation is infused into an organisation. This is because the space for rhetorical exchange is gradually filled up with 'taken-forgrantedness' that firmly installs an innovation into an institutional setting.

In summary from the above, it is clear that the importance of rhetoric is not only reflected in the way adoption decisions are formed and influenced, but also in the way by which an innovation is implemented, contested, embedded, legitimised and eventually institutionalised. While prior studies have provided useful insights in portraying the conceptual components that afford the general functioning of rhetorical practice, what is less articulated is how organisational actors enact and replenish rhetorical practice when some of these components appear to be highly problematic and dysfunctional. Specifically, what interests us within the highly contentious innovation of talent management are situations where the arena for the public display of alternative and competing rhetorics is limited. Even though few will challenge the strategic importance of talent management, understanding how to deal with its contentious characteristics rhetorically remains limited, in particular to seek and sustain the required legitimacy in order to institutionalise it (Tolbert and Zucker 1996). How do rhetors promote the benefits of talent management? With its apparent attractiveness, at least to its immediate stakeholders, would promoting its potential benefits to and sustaining commitment from those chosen as talent be difficult at all? How would the rhetoric associated with talent management address the diminishing career opportunities for those who are not included in the initiative yet happen to be the majority of the workforce? How would inconsistency of ideologies and conflicts of interests amongst different stakeholders be compensated or covered up through the use of rhetoric? To address these essential questions, the following section outlines our methodological considerations and processes. 


\section{Methodology}

Our study is comprised of a single, case study which explores the rhetorical practices inherent in the implementation of a talent management initiative. By garnering rich insights into the experiences of a variety of stakeholders engaged in the initiative, we are able to document, examine and conceptualise the rhetorical underpinnings of the talent management programme which is not previously attempted.

\section{Research context}

Epicurea is a highly successful North American corporation founded in the 19th century which has increasingly internationalised its business operations in agriculture, finance and risk management and grown extensively via acquisition of small and medium-sized businesses. For this multi-national organisation the pattern of global growth resulting in a workforce of 160,000 employees in 67 countries has been achieved in many national markets in Eastern and Western Europe, Africa, South America and the Asia Pacific rim. Addressing this continuing global growth and the diverse range of requirements for skills derived from continuous changes in market demands has long been a challenge for Epicurea executives. Talent management was formally added to the global HR portfolio of services in 2005, although the concept has been partially practised since 2002 .

\section{Data collection}

Our main data collection method was semi-structured interviews. In total, 19 respondents were interviewed, with 19 of the respondents from six regions (North and South America, UK, Central Europe, Middle East, Africa) having a dual role in managing their own and others' talent. Amongst the 19 , nine were global executives and ten were managers who worked in various functions on one site (processing plant operation, logistics, sales, HR, finance and IT). The average length of interview was 65 minutes and all were recorded and transcribed. Three focus groups were also held (firstly with five staff in the plant control room, then with four staff in the processing plant area and finally with three senior plant management) in order to gain additional insights into career, mobility and 
development activities in Epicurea and check our understanding about such talent management processes and practices from the interviews.

\section{Data analysis}

The initial phase of analysis focused on deriving concepts from a sample of interview scripts and grouping these emerging concepts into preliminary thematic categories. Not all categories bear the same level of potential to yield valuable theoretical return (Strauss and Corbin 1998), therefore, prioritising categories that show strong potential for progressing to later phases of analysis is essential. In particular, using a more phenomenon-focused approach (in our case rhetorical obfuscation) to reposition identified categories permits the process of prioritisation which is essential to manage the continuous emergence of theoretical opportunities commonly encountered in exploratory research (Locke 2001). The second phase of analysis was to input the collected data into NVIVO8 software in order to manage and filter the data based on the preliminary themes developed earlier. During this phase of analysis, iterating between the emerging findings and existing theories, in this case the notion of rhetorical obfuscation and theories of rhetorical practice, allowed us to become more precise in framing the researched phenomenon (Orlikowski 1993). As suggested by Glaser (1978), the role of previous studies, in our case specifically from rhetorical practice, is not merely for its sense-making potential, but also the value in operationalising coding. This technique of iteration does not suggest that the earlier phase of analysis was ignored or abandoned. Instead, these initial results were repositioned to become supporting roles to strengthen the conceptual grounding of our new insights.

Given that exploratory research is not typically geared towards generalisation, as with reports from other exploratory accounts (e.g. Van Maanen 1991; Pentland 1992), our emphasis is placed on constructing the storyline to depict the unique features of the researched phenomenon and its underlying dynamics and processes. Such an aim is reflected in the way in which the experiences of our research subjects in their engagement with their talent management initiative were re-created. With the focal phenomenon of rhetorical obfuscation in mind, the story unfolds through elaboration of 
the ways in which such a technique was deployed in a corporate initiative where its application was not expected nor publicly debated. Following our earlier point, we do not suggest that our findings can be generalised to all talent management programmes in different organisational settings. Rather, through narrating the story, we hope to fulfill our proposed aims to extend the general foci of how rhetorical practice in the context of HR innovation is inquired upon in order to provide a platform for further inquiries to build upon.

\section{Case findings}

\section{The context of the talent management programme at Epicurea}

There were three distinctive yet interrelated objectives identified for Epicurea's global talent management programme. Firstly, to take a more proactive approach in identifying, developing, nurturing and retaining key staff to ensure a well stocked 'talent pool'. Secondly, to achieve the first objective, Epicurea needed to become more effective and systematic in addressing its ever changing skill requirements through better human capital management of talent, particularly via succession planning for top roles. Thirdly, in order to achieve 'consistency of quality' and 'standardisation' in its implementation of its 'management ethos' for 'operational excellence', not least in the growing number of newly acquired businesses, to ensure that effective systems were in place for the mobilisation of key staff on a global scale across the enterprise. Following Tolbert and Zucker's (1983) distinction between different triggers for institutional change, it is clear that the main objectives underlying Epicurea's talent management initiative are to address some 'task-related requirements', rather than merely for 'growing legitimacy' in their reputation in the labour market.

Two building blocks were seen to be essential to actualising these objectives. The first was to begin the initiative by producing a suitable 'architectural blueprint' for constructing talent management policies across geographies, defining talent to enable identification and begin the 'stocking up' of the talent pool. The second was to operationalise the initiative through nurturing and developing those chosen as organisational talent, then monitoring their progress and suitability to stay within the talent management programme. As exemplified by the European Regional Director of HR, 
the main underlying process for HR specialists to operationalise the talent management programme is outlined as follows:

We see talent management as first of all identifying who are those people with thatthe ability and with potential to rise in the organisation and once we have identified those we can manage that talent in the sense of 'how do we develop them?', 'how do we move them around the organisation?', 'how do we use them to the best of their ability and also the businesses ability?'. Who are they? What are they doing now? Where do they think they can go? How do we develop them to get there and move away from there?

Leadership and management development took place in two distinct forms: formal management educational development and the more informal, including assigning ad hoc projects, coaching and mentoring. Of the more informal, two forms of talent development were particularly favoured by Epicurea executives: 'stretch projects' and 'geographical mobility'. The aim of a stretch project is to take the individual out of their day-to-day responsibilities and make them accountable for a project which is more strategic in orientation. Such an action also has the objective of testing an individual's potential and unleashing any particular aptitude for operating at one or two higher job levels. It was argued that geographical job mobility in Epicurea provided a number of benefits, not least the development of cultural sensitivity. Availability for geographical mobility was a contractual requirement for all Epicurea talent.

\section{Phase one: architecting talent management}

This phase began with the process of recruiting to the talent pool, based on the nomination of candidates from each business unit and using the selection criteria drawn from Epicurea's Leadership Model, which had been devised for use by all businesses and functions. To uncover the underlying complexity requires not only details of how the process was carried out, but also gain clarity about how talent and leadership were defined, localised and operationalised. Talent in Epicurea is defined in number of ways. According to the talent planning manual, the official definition of talent comprises 'individuals who can demonstrate high levels of potential to make a distinctive difference to the 
business, combined with proven capability for high performance in any role'. However, various interpretations of the official definition and its local application were expressed by our interviewees. For example, some senior executives said that talent has 'more than ability', being not only an outstanding performer with the ability 'to think out-of-box' and 'to make differences to the business' but also be able 'to demonstrate the potential to rise more than two managerial positions'. Some managers' notions of talent were restricted to those with leadership capability, with one arguing that organisational 'talent are leaders in the making', but not all had the capability to progress from manager to leader. When referring to the official definition of leadership, an ideal leader, as specified in the talent planning manual, should be equipped with, and successfully demonstrate, qualities such as being 'courageous', 'curious and passionate to learn more than taught', and 'relentlessly determined', together with rhetorical capacities to 'motivate staff towards high performance and excellence' and to keep them feeling 'enthusiastic' and 'optimistic'. When comparing and connecting leadership with talent in Epicurea, it was therefore the case that leadership has been a major concept that many executives and managers used, not only to make sense of talent management but also to embed talent management into their construction of organisational reality. In Epicurea's rhetorical world, then, these two concepts are virtually inseparable. This is also evident in the way the notion and process of talent management is operationalised through their talent pool architecture and the strong influence of the notion of leadership on its construction.

Slightly over $10 \%$ of Epicurea's total workforce was nominated by their line managers to broadly fit into the two criteria (high performance and high potential). The list was then finalised by HR specialists who conducted interviews and tests, leaving the top $6 \%$ of employees across all businesses and geographies of Epicurea. As shown in Figure 1, included in the four layers of distinctive yet interrelated talent pools, are the 'top 100' leaders, 300 'next generation leaders' (NGLs), around 750 'high impact performers' (HIPs) and about 8000 'emerging leaders' (ELs). While some of the top 100 already occupy corporate level and regional general manager positions, the next generation leaders are those who might be currently leading a business unit with the potential to move up the ladder with executive coaching and mentoring. The HIPs are defined by Epicurea as individuals whose departure will cause severe problems to the business, in particular if their 
replacements are not in position within six months. The category of emerging leaders covers individuals who are 'exceeding expectation', yet still have potential to be 'stretched' further.

\section{Insert Figure 1. Layers of talent pools across Epicurea here}

The idea of 'layering', as a crucial architectural attribute of the talent pools in Epicurea's talent management initiative not only enables identification of appropriate talent development interventions for each pool, but also indicates the importance of continuity in talent placement such as 'succession planning'. Hence, the construction of a 'talent pipeline' is more than merely 'spotting' talent, for equally important is the identification of any 'gaps' and 'cracks' in the pipeline. Given that the occurrence of such gaps and cracks will create direct and immediate impact on the day-to-day operation of the business, the ability to anticipate this happening is therefore vital. As the European Regional Head of HR indicated:

I think that there is a realisation, certainly in my business, that unless we have got the right people for the right places in the next 5 years we are going to be in trouble.

\section{Phase two: operationalising talent management}

The second phase was to implement the architectural blueprint drawn up in phase one. Here we address three key aspects, namely the approach to implement talent management, the development of talent and monitoring talent's engagements.

The secrecy approach

... it [talent management] is just not for everyone.

This statement from one of Epicurea's HR specialists demonstrates the clear divide between the top $6 \%$ and the rest of $94 \%$ in the organisation. It presents a challenge for operationalising talent 
management in the company and has serious implications for issues such as perceived unfairness and inequality in career development opportunities. Therefore, controlling, and more specifically obfuscating, the feelings and perceptions of the remaining staff is crucial. Referring to the account of Tolbert and Zucker (1983), what seems to be interesting in Epicurea's case is that what needed to be addressed and achieved by talent management was clear and legitimate to many of the organisational stakeholders. However, what appeared to be problematic and contentious was the underlying philosophy and the approach deployed to address it. At Epicurea only a very small number of people, mostly HR and line managers, know who is in a talent pool, with even those regarded as organisational talent not being told that they have become 'the chosen ones'. As the Corporate HR Director noted:

We don't tell them but we expect managers to convey certain messages and have certain conversations in a way which is probably quite apparent whether they are considered to be high potential or whether they are considered to be a bit of a dog at the moment, but more importantly we help managers. Talent identification is a little bit more grey, but so what!

The rationale behind this secretive approach offered by the interviewees range from 'managing expectation', 'how about those not in the talent pool', 'flexibility', 'we develop them but not promise them' to the official version of 'we are working on it'. As another Regional Head of HR explained:

You're not told your talent designation - you're told that you're a high potential person, but we wouldn't say that someone is part of a talent pool, which I personally disagree with. I feel that if we identify them, we should let them know and treat them as adults, and if they decide to go round and are arrogant then they should be taken off.

Despite the emphasis on and efforts of Epicurea's HQ to maintain this secrecy, according to some of our interviewees at the subsidiary level, information about who is in or out of the talent pool 
seems to be a poorly kept secret after all. As one interviewee from the Finance Department of a business unit explained, 'it's just not really discussed, but I think everybody within our department knows who we've picked out to be in the talent pool, and why those people were picked out'. Another interviewee, a regional sales manager who was a talent pool member, explained, 'we're not very transparent on this, but I am aware from discussions with my previous manager and my current manager that I am held in high regard and that they wanted to develop me'.

One can argue that the lack of transparency in talent management is not unusual, as it is essentially a 'clandestine process of handpicking and grooming tomorrow's CEOs behind closed boardroom doors' (Williamson 2003, p. 34). However, it is apparent from the case that sustaining the secrecy of talent management membership was far more challenging than anticipated for a number of reasons. Firstly, some of the subsidiaries have been operating the talent management process based on a much more open approach compared with their HQ and regional counterparts. Secondly, based on the leadership development programmes that organisational talent participates in, they can easily find out who else is in the talent pool. More details related to this will be elaborated later under the subheading of 'Developing talent'. Thirdly, those who have been denied the opportunities to attend some of the programmes, by comparing themselves with others, can discern the ways in which their career development path has been differentiated. What is also interesting from the case is how such rhetorical situations were dealt with, as the secrecy approach was gradually becoming unsustainable, given its lack of legitimacy. In order for the organisation to compensate for such a lack of legitimacy as much as to shift the attention, another set of rhetoric was created and mobilised. To prevent any potential outbursts from the $94 \%$ is in some cases as critical as managing the engagements and commitments of the $6 \%$ in the talent pool. Even though $94 \%$ of Epicurea's workforce still have the opportunity to receive incremental promotion, most of the senior and strategic roles, as one HR specialist put it, are basically 'out of their reach'. Despite the fact that the $94 \%$ was never the focal point of the initiative, mobilising their motivation to work by creating a sense of engagement is still vital. The story most commonly deployed by HR community in Europe was a relevant example:

Just next door to us, LG are building an assembly plant. They are going to employ 3000 people and another 9000 people supplying that plant in that area. So 
how do we keep hold of our well trained, very well educated, fluent English speaking, high quality engineers, manufacturing, finance, HR, whose skills are transferable?

A story like this is rich in its rhetorical substance and obfuscating power, in particular to demonstrate that a battle can happen just down the road. The close proximity of the battle ground with an extensive display of aggressive talent-seeking behaviours not only reinforces the sense of emergency in the severe shortage of talent supply (Ernst \& Young Global Relocation Survey 2009), it also helps to translate a globalised issue into a meaningful, ready-for-action, localised reality. For a practice which used to receive very little attention from Epicurea's top management, talent management has now gained a lot of momentum. Suddenly, there was a sense of urgency and reality been staged to indicate that everyone, even the $94 \%$, has become part of the talent war, and has the chance to be headhunted for a better future.

\section{Developing talent}

As we have seen, the two Epicurea talent development approaches most heavily utilised are "the stretch project' and 'geographical mobility'. While they have been postulated by Epicurea, particularly the HR and line managers, as something extremely valuable for identified talent, different insights contrasting with the official rhetoric also surfaced. By reflecting on the way talent is treated in the day-to-day workplace, it is clear that rhetorical obfuscation plays a key role here to selectively highlight the benefits of stretching and mobility for the gain of Epicurea, while the impacts and implications for the individuals are severely downplayed. For example, one respondent is characterised as a 'management cover-all'. She told us that:

Dual and multiple roles just simply rolled into one job....I was working as an engineer, but I was also covering the works of a system manager... Then, one of the maintenance coordinators, which is obviously a lot lesser role, left the company. He used to look after contractors on site, so suddenly they didn't have 
anyone to look after contractors, so 'do you fancy doing us a favour, could you look after these contractors?'

In addition to feeling over-stretched, some perceived that being part of the talent pool is also a licence for the company to treat one as an acquiescent 'general dogsbody'. As one interviewee said: There've been roles where I've thought, well, it's not really going to develop some of the roles because, basically, they've got no-one else to do it. So they'll ask me because they probably know I'll say yes.

In addition to the feeling of being over-stretched, mobility is the issue that most concerned Epicurea's talent. Mobility can take place in many different forms, such as business travelling, shortterm assignment and expatriation. We will only highlight the aspect of expatriation, due to its significance in the conversation amongst different group of stakeholders we interviewed.

In Epicurea, talent is required to be constantly on the move and venturing into new geographies, as evidenced by statements such as 'moving East is the new moving up'. As a senior manager stated:

I don't think an effective leader can come to a location at the age of 20 and leave at 55 or 60 . I don't think you can stay at the same location and be effective.

In addition to the acclaimed benefit of developing 'cultural sensitivity', what seems to be constantly advocated by the senior management and HR are the opportunities to build up 'networks' and 'connections' through expatriation. Indeed, being mobile is a prerequisite commitment that recognised talent have to make in order to continue their membership of a talent pool. As a senior HR manager explained:

Mobility is a key part of someone's future development potential. So we will always have a discussion in the appraisal about 'how mobile are you?' 
Given that the issue of mobility was transparent and clearly understood by all, it is crucial to illustrate the reactions of some organisational talent. Based on a recent internal staff engagement survey, the percentage of talent expressing their unhappiness towards mobility gave cause for alarm. A number of different issues were evident. Firstly, more than a third of participants expressed high levels of dissatisfaction with the requirement. Secondly, the company's over-emphasis on face-to-face meetings rather than technological alternatives, such as conference calls and e-meetings, was resulting in high levels of travel. Thirdly, the reluctance of some HQ-based talent to move meant unfair demands on others. However, the most crucial issue is that more than three-quarters of talent are in dual-careers. As indicated by four of the participants, their willingness to be mobile and their level of mobility has changed in relation to their life cycles, with a diminishing willingness to move because of responsibilities for young families. Mobility has been transformed from something that many talent are rhetorically engaged with to something that truly matters to their family life. As one said 'Turkey just does not have the right education system for my young daughter', while another noted that 'my wife does not think that Azerbaijan is safe for the family'. These changes in perceptions and rhetorics even include reluctance to attend some of the overseas training courses and part-time degrees which many participants initially considered as the perks of being part of the talent management programme. For instance, one of the participants indicated:

A couple of years ago, I was thinking about an MBA. But to be honest, what am I going to get out of it? Why would I do that - I've got a young family. I've got two colleagues who have done it and it nearly killed them!

While some are alert to rhetorical obfuscation, others can be slow in recognising it. One manager in the talent pool was relocated to Chile, leaving his family in Argentina and only flying back home every two weeks. Without friends to socialise with, he spent most of his weekends in Chile working. His ironical statement "is this what you called developing "cultural sensitivity?"” highlighted his distain of the process.

\section{Rhetorical reinforcement}


Expressions of 'feeling special', 'feeling different', and 'being recognised and appreciated' were commonly deemed by the interviewees as a positive aspect of being regarded as talent. This 'feel good' factor is one of the positive images that Epicurea aimed to portray and thereby engage its talent. As outlined in one of the promotion materials:

No matter who you are, where you are from or how you like to work, you're one of a kind. You have your own ideas, talents and experiences, and that's what we value most about our employees.

In particular, the top two layers of talent (Top 100 and the Next Generation Leaders as shown in Figure 1) are 'privileged' to be invited to the 'Big Talk', in the format of a conference call, carried out by the Chairman. Even though the majority of the participants will not have an opportunity to speak a word during these 'Big Talks', they are still the selected few to 'be inspired' and 'get excited' from the preview of the latest strategic developments of Epicurea.

Annually, the HR team conducts a 'career talk' with talent. This comprises interviews and tests to obtain, update and evaluate changes in personal circumstances and emotion states to assess their suitability to stay in the talent pool and is a vital channel where reinforcement of commitment can be put into action. For instance, by indicating the development courses that talent will be sent to, it also reflects on career opportunities that will become available to them. However, the subtlety behind some of the career talks is less articulated, in particular to talent. As the Head of HR for South American region put it:

You plan to do something with them in the future, although you are not making any promises. It is good for people to know that they have been identified as somebody who is going to progress, or you hope that they are going to progress, depending on the state of the business.

Given the significance of these career talks on determining the talents' future career opportunities, to satisfy HR's assessment by casting only a positive rhetorical display, in particular by reassuring their willingness to be stretched and to be geographically mobile, is essential. While a 
convincing rhetorical display might not reflect their true feelings, it nevertheless helps to create and sustain an affirmative image to try to ensure talent remains in the talent pool. What is clear from our observation is that the technique of rhetorical obfuscation is no longer the monopoly of some users. Rather, it has become a popular tactic for many participants in the talent management programme to draw on.

Those members of the talent pool who are also managers of talent at the business unit level have particular challenges apart from the myriad of issues which can personally arise from the impacts of the mobility policy. Examples of areas of common amongst line managers ranged from their feelings of awkwardness when having to tell those who didn't make it to the talent pool to their dissatisfaction about changes to training and development practice as a result of implementing talent management. As one Plant Manager told us:

I think what is easy to do is to forget about the people who aren't going to make two level jumps.... The problem with that is that you create a hierarchy of training and only the chosen few get training. And that can engage a small percentage of the workforce but disengage a far larger percentage of the workforce. So talent management is too big to say talent management is for these people. What I did before was to try and develop everybody on site and to get them all to a core level of ability.... This latest formal talent management system has stopped all of that, and I feel bad about it really.

The above point elaborates a divide that echoes Pfeffer's (2001) warning about the hazardous conditions which can potentially be caused by the implementation of a talent management initiative. As discussed further by Mellahi and Collings (2010), in addition to the above divide that separates those who are recruited to the talent pool from those who are not, other forms of divide can also occur and potentially result in the failure of talent management. One such divide is caused by the conflict of interests between the HQ and subsidiaries, arising from a tension relating to whether local talent should be made available to be mobilised by the $\mathrm{HQ}$, or retained at the subsidiary level to fulfil its self-serving interest. According to Mellahi and Collings (2010), such divides are further worsened by 
the geographic and social distances that are commonly observed in organisations operated in a multinational context. The divides indicated by them also symbolise the tension and dilemmas faced by various line managers whom we have interviewed. On the one hand, they are responsible for spotting and developing the talent who will contribute to the corporate talent pool. On the other hand, they are also running the risks of losing the talent reporting to them who are have been identified as 'stretchable' individuals with great capacity to be the useful 'management cover-all'. Given that these emerging leaders and HIPs are those whose departure can cause serious impact at the business level, retaining them, in particular keeping them on site, is crucial to the line manager responsible for ironing out unexpected demands and problems that disrupt the continuity of local operations. In theory, when a talent is removed across the globe to a different location, a new talent from a different geographic region will be put in. However, from our conversations with some of the line managers, it is clear that the level of trust on the system to perform mobility processes in a highly synchronised fashion is yet to be established. As one Head of a business unit noted:

From our business point of view, looking at talent and this is really hitting home now, is that the business is changing so much across Europe with business pressures, with moving East, business moving into Eastern European countries and China and those places is how do we actually get talent into the business? Where do we get it from? We've got to make sure we retain it otherwise the business is moving so fast and moving rapidly East as a business - how do we get the talent in and retain it in certain areas?

The dilemma of keeping or letting go organisational talent at business level produced various conflicts between some line managers and HR specialists, with a variety of views being expressed. As reflected in the following quote from one of the HR directors:

The managers can't hold on to their good people, they've got to let them go for the good of the company overall and the talented ones want to move around so it's not fair to hang on to them. It's selfish. 
By contrast, managers do have their own concerns. Even though most of them felt obliged to give up their best people, they did not appear to have truly bought into the idea that talent management is really good for everyone. One expressed his annoyance, saying:

This isn't about engagement. This is about identifying and developing people to take away from me.

Given that mobility is a contractual obligation to stay employed by Epicurea, is it taboo for organisational talent to talk about their lack of mobility? From our observations, it is clear that this issue will largely depend on who is involved in the conversation when such issues are discussed. There were several reported cases where talent had 'come clean' with their line managers about not really being mobile if a request was made for expatriation, but no-one mentioned it had been raised during the annual career talk with HR. The technique of rhetorical obfuscation in situations like this can be highly valuable for both talent and manager, then, but it does require discursive creativity to operationalise it in order that no-one is seen to be going against the mobility policy. For instance, in one post-career talk conversation a line manager said to one of his talent who said he was not really mobile:

Well, there will always be a need locally for people like yourself. You've got longevity on the site, you can remember how it was, and things that get done.... Who's to say you don't become the production manager, or the maintenance manager, or ultimately, do all the managerial roles that you've said.

Thus the manager is using rhetorical obfuscation to both minimise the serious nature of the talent's refusal to be mobile and showing his allegiance to one of his own staff against company policy.

Even though this issue is not entirely unknown by the HR, it was not acknowledged and their reaction was very much 'business as usual'. As one of the HR directors said: 'you've got them into buckets. So what do you do?' Essentially, HR have their own agenda and interests to look out for. It is therefore crucial to unravel the motivation and stance of HR in the context of talent management. While 'a war for talent' was occurring outside in the global labour market, there was also an ongoing battle within the organisation for the HR community to prove their strategic added-value. As 
Williamson (2003, p. 34) pointed out, it is an open question whether talent management 'is now too important to be left to the human resources function'. From the global HR meeting in 2005, HR's intention and determination was clear. It was announced by its Global Head of HR that they needed:

To become true business partners to Epicurea businesses by getting to understand how cutting edge human resource processes can be applied to create a competitive advantage for those businesses.

Given that the focus here was not to surface more cracks and gaps in the talent pipeline, as acknowledged by another HR director, not taking any action somehow served the purpose of projecting a certain level of harmony, even with the growing complaints and unhappiness developing towards the mobility policy. One of the HR specialists indicated that:

Straight talking is always an issue here... Most people in Epicurea they're hired as trainees and they're here until they retire. So a lot of the guys are Business Unit level and above - they've known each other for $20-30$ years. So there is that baggage, too. How can I tell someone I've known for a long time that 'you have done a terrible job'?

Despite this problem, the lack of straight talking also provides the HR community with some advantages to mask the scale of issues that many talent experienced.

\section{Discussion and conclusion}

Reflecting on the challenges of talent management, we have noted several conceptual elements that are crucial to understand and appreciate how rhetorical practice in general and rhetorical obfuscation in particular can unfold in a case organisation. The starting point is how and where the boundary of such a talent management initiative is drawn and the possible impacts of dividing the top $6 \%$ of organisational talent from the remaining 94\% of the workforce. Echoing prior studies (Pfeffer 2001; Mellahi and Collings 2010) that pinpoint the dysfunctional side effects associated with talent 
management strategies and processes, the practice of rhetorical obfuscation is as important to justify its rationale and ideology as to cover up the lack of legitimacy in attempts to institutionalise talent management. The story of the pigs managing George Orwell's Animal Farm is a useful metaphorical device to elaborate some of our findings. In that text 'all animals are equal, but some animals are more equal than others' (Orwell 1971, p. 99). Orwell's text also provides us with other fine examples of rhetorical obfuscation for comparison.

Firstly, where the pigs in all management positions attempt to control other animals by persuading them that there is a war to be feared outside the farm gate, we see how Epicurea management rhetorically emotionalise their staff that there is a 'war for talent' raging outside the factory gates. Given that the war is for everyone and not just for the $6 \%$ of the organisational talent, the attention has been conveniently drawn to the outside world rather than opening up the debates for the political correctness of the approach behind the adoption of talent management and the seeking of institutional legitimacy underlying the talent management initiative. As pointed out by Sillince (2005, p. 612), one of the key functions of rhetorical practice is to achieve unification by providing stakeholders, regardless their levels of engagement, with a 'transcendental big picture' or a 'simplified and understandable official view' in order to guide the way by which circumstances are made sense of and actions are taken. Hence, for rhetorical obfuscation to work effectively, in particular in addressing rather distinct groups of audiences with diverse interests, such as between HQ and subsidiaries in Mellahi and Collings' (2010) account, a relevant story that serves as a transcendental big picture is strongly needed.

Secondly, in the pigs' management group, some pigs argue that they should have the best food as a reward for undertaking the more difficult management tasks of leading and strategic planning. Again, we see a similarity in our study, where we identify how managers skilfully practise acts of rhetorical obfuscation in a variety of ways. For instance, development opportunities, such as leadership coaching, mentoring and MBA at leading business schools, are only available for those with valid membership of the talent pool. Even with high levels of dissatisfaction with some aspects of the initiative, as elaborated in the case, most of the managers show no hesitation in elaborating their full commitment and compliance to the overall agenda of talent management. Of course, this is 
evident in occasions where such performances are required. Yet, at the same time, many are actively seeking and developing opportunities that can accommodate their changing personal agenda and circumstances. To do so, such organisational talent need to be equally skilful in performing the act of rhetorical obfuscation to their line managers. Interestingly, rhetorical obfuscation appears to be a bygone monopoly. In a rhetorical world, different discursive realities can indeed co-exist, as far as the rhetors are creative and skilful enough to get the show running.

Thirdly, the lack of an open arena for public rhetorical exchange characterises another crucial element shown in this case, and closely overlaps with what has been portrayed in Orwell's (1971) Animal Farm. While it is not unusual for organisations to implement an innovation by using a topdown approach, as often seen in the example of corporate restructuring (Erkama and Vaara 2009), it is less often that we see an initiative, in this case talent management, implemented based on such high levels of secrecy. From our findings, it is vital to note that the lack of openness for rhetorical contestations is not merely shown in the unequal rhetorical rights different actors are able to draw on and exercise. Equally important, it also depicts a rather weak foundation on which talent management can be legitimised and institutionalised. Such a peculiar contextual condition provides a vital explanation of why rhetorical obfuscation becomes so important to progress and sustain talent management, or at least to achieve some degree of harmonisation regardless to how temporary it is. As shown in the case, its importance is not only limited to the champions of talent management, but also for the dissatisfied organisational talent show in attempting to capitalise on what is available for them to salvage. This does lead us to question the consequences that an innovation, such as talent management, leads to, in particular when it is less openly debated and contested, as elaborated in this case. Our findings suggest that, despite the official interpretation of talent management remaining unchallenged due to the lack of opportunity for organisational actors to do so, it actually affords more room for different actors to manipulate.

What is also evident in the case study is the way in which the obfuscation of rhetoric eventually becomes normalised at the organisational level. In this, the added role played by HR in the talent management initiative as the police of rhetorical practice cannot be under-estimated. These interwoven elements have certainly given our context, the talent management programme, a rather 
unique, surprising yet meaningful setting to examine rhetorical practice in the organisation. Undoubtedly, rhetorical obfuscation is a discursive practice and a cultural fabric that actors draw on to interpret, internalise and make sense of their actions (Smircich and Stubbart 1985; Weick 1995). As found throughout the case, the development and deployment of talent management rhetoric is not merely the reflection of organisational culture upon which the rhetoric draws. More crucially, the very act of rhetorical obfuscation 'reproduces and reinforces the cultural assumption on which it is based on' (Cheney et al. 2004, p. 90).

Another finding from our case analysis is the extent to which various approaches and elements of a talent management programme are seamlessly orchestrated to create the intended effects. As we are reminded by Nelson and Lambert (2001, p. 92), 'successful bullies display an artful skill of decoding and exploiting the rhetoric contained within their environment'. As exemplified in our case, incentives used by the managers to rhetorically obfuscate organisational talent range from fast track career development, exclusive training programmes and networking opportunities, to more specific acts, such as 'big talk' and 'career talk', for particular audiences. However, what should not be ignored is how some of the elements, such as mobility, 'stretching' and cultural sensitivity, are invoked by highlighting not only their benefits but also downplaying their implications to an individual's ever increasing workload and general wellbeing, such as work-life balance. Has talent management become a new tool to be deployed by powerful organisational actors to exploit the most elite in their workforce?

Contributions offered by this study are threefold. Firstly, with relatively little theoretical grounding available to conceptualise talent management, we believe that our account is important both in the insights we detailed, as well as the theoretical and practice significance it highlighted. Secondly, by exploring the rhetorical underpinnings related to the adoption and institutionalisation of talent management, we have added to the rich intellectual tradition of rhetorical practice by presenting the notion of rhetorical obfuscation. In particular, by elaborating an organisational context where open contestations and exchange of different rhetorics are not fully functional, our study has challenged the conventional assumption that all rhetors are provided with rather equal opportunities to put forward their rhetorical display. Also, we have elaborated how actors deployed rhetorical obfuscation as a 
means of compensating and coveringing up the lack of legitimacy in the failing process of institutionalisation. Finally, by introducing the theory of rhetorical practice and the notion of rhetorical obfuscation to the HR community, we believe that we have demonstrated the usefulness associated with the perspective of rhetorical practice associated with the institutionalisation of innovation, but also created a launching pad for other HR researchers to build on. As noted by Suddaby and Greenwood (2005, p. 62), 'we need further work on the consequences of rhetoric'. Despite the fact that we have provided a rich account in this regard, we believe that more needs to be done. Clearly, further examination of rhetorical practice in different types of HR-related innovation will help to extend our general understanding of how values of an innovation can best be discursively constructed and publicly contested to facilitate its adoption. Moreover, it will be beneficial to expand our knowledge of how different rhetorical roles that HR need to play in order to engage in various organisational initiatives and their relevant stakeholders.

\section{References}

Abrahamson, E. (1996), 'Management fashion', Academy of Management Review, 21, 254-281.

Alvesson, M., and Kärreman, D. (2000), 'Varieties of discourse: On the study of organizations through discourse analyses', Human Relations, 53, 1125-1151.

Cappelli, P. (2009), 'A supply chain approach to workforce planning', Organizational Dynamics 38, $8-15$

Cheney, G., Christensen, L., Conrad, C., and Lair, D. (2004), 'Corporate rhetoric as organizational discourse' in Organizational discourse, eds. D. Grant, C. Hardy, C. Oswick, and L. Putnam, London: Sage, pp. 79-103.

CIPD (2007), Talent: Strategy, management, measurement, London: CIPD

Collings, D., and Mellahi, K. (2009), 'Strategic talent management: A review and research agenda', Human Resource Management Review 19, 304-313.

Eccles, R., Nohria, N., and Berkley, J. (1992), Beyond the hype: rediscovering the essence of management, Boston: Harvard Business School Press.

Erkama, N., and Vaara, E. (2010), 'Struggles over legitimacy in global organizational restructuring: A rhetorical perspective on legitimation strategies and dynamics in a shutdown case', Organization Studies, 31, 813-839.

Ernst \& Young (2009), Global mobility effectiveness survey 2009. 
Freedman, A., and Medway, P. (1994), Genre and the new rhetoric, Bristol, PA: Taylor \& Francis.

Glaser, B. (1978). Theoretical sensitivity, Mill Valley: Sociology Press.

Grant, D. (1999), 'HRM, rhetoric and the psychological contract: a case of "easier said than done", The International Journal of Human Resource Management, 10, 327-350.

Green, S. (2004), 'A rhetorical theory of diffusion', Academy of Management Review 29, 653-669.

Herrick, J. (1998), The history and theory of rhetoric, Needham Heights, MA: Allyn and Bacon.

Hirsch, P. (1986), 'From ambushes to golden parachutes: Corporate takeovers as an instance of cultural framing and institutional integration', American Journal of Sociology, 91, 800-837.

Huang, J., Galliers, R., Hsu, C., and Newell, S. (2011), 'The rhetorics of system adoption and diffusion in the Taiwan banking industry' Hawaii International Conference on Systems Sciences.

Locke K. (2001), Grounded theory in management research, London: Sage.

Mone, M., McKinley, W., and Baker III, V. (1998), 'Organizational decline and innovation: A contingency framework', Academy of Management Review, 23, 115-132.

Nelson, E., and Lambert, R. (2001), 'Sticks, stones and semantics: The ivory tower bully's vocabulary of motives', Qualitative Sociology, 24, 83-106

Newell, S., Swan, J., and Galliers, R. (2000), 'A knowledge-focused perspective on the diffusion and adoption of complex information technologies: The BPR example', Information Systems Journal, 10, $239-259$.

Newell, S., Tansley, C., and Huang, J. (2004), 'Social capital and knowledge integration in an ERP project: the importance of bridging and bonding', British Journal of Management, 15, 43-57.

Orlikowski, W. (1993), 'CASE tools as organizational change: Investigating incremental and radical changes in systems development', MIS Quarterly, 17, 309-340.

Orwell G. (1971), Animal farm: A fairy story, London: Martin Secker \& Warburg.

Pentland, B. (1992), 'Organizing moves in software support hot lines', Administrative Science Quarterly 37, 527-548.

Rajagopal, P. (2002), 'An innovation-diffusion view of implementation of enterprise resource planning (ERP) systems and development of a research mode', Information \& Management, 40, 87114.

Rauch, M. (2006), 'Retention necessary', Incentive, 180, 18-23.

Rogers, E. (1995), Diffusion of innovations, New York: The Free Press.

Scullion, H., Collings, D., and Caligiuri, P. (2010), 'Talent management', Journal of World Business, $45,105-108$.

Sillince, J. (2005), 'A contingency theory of rhetorical congruence', Academy of Management Review, $30,608-621$. 
Strauss A., and Corbin J. (1998), Basics of qualitative research: Techniques and procedures for developing grounded theory, Sage: London.

Suddaby, R., and Greenwood, R. (2005), 'Rhetorical strategies of legitimacy', Administrative Science Quarterly, 50, 35-67.

Tansley, C., and Newell, S. (2007), 'A knowledge-based view of agenda-formation in the development of human resource information systems', Management Learning, 38, 95-119.

Vaara, E., and Tienari, J. (2008), 'A discursive perspective on legitimation strategies in MNCs', Academy of Management Review, 33, 985-993.

Van Maanen, J. (1991), 'The smile factory: Work at Disneyland', in Reframing organizational culture, eds. P. Frost, L. Moore, M. Louis, C. Lundberg, and J. Martin, London: Sage, pp. 58-76.

Williamson, L. (2003), 'Tap into talent', Human Resources, 49, 34.

Zanko, M., Badham, R., Couchman, P., and Schubert, M. (2008), 'Innovation and HRM: Absences and politics', The International Journal of Human Resource Management, 19, 562-581. 
Figure 1. Layers of talent pools across Epicurea

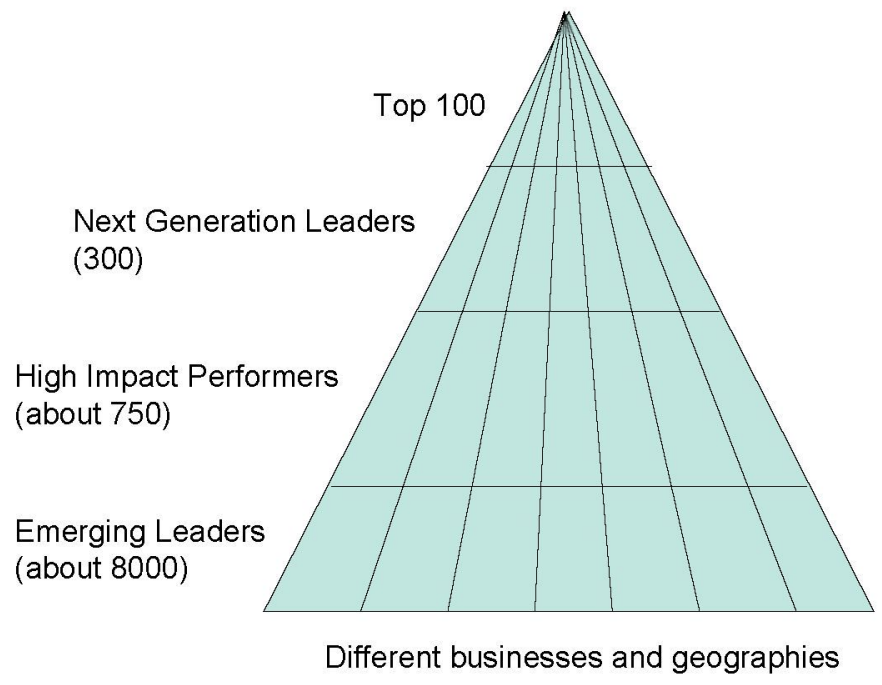

